\title{
Laparoscopic surgery in distal pancreatic tumors
}

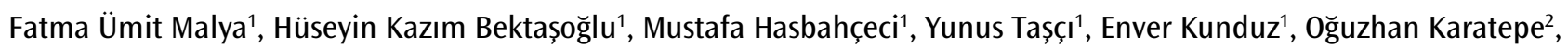
Kemal Dolay ${ }^{1}$

\section{ABSTRACT}

Cite this paper as:

Malya FÜ, Bektaşoğlu HK

Hasbahçeci M, Taş̧̧ Y,

Kunduz E, Karatepe 0, et al.

Laparoscopic surgery in distal

pancreatic tumors. Turk J Surg

2017; 33: 288-291.

'Department of General Surgery, Bezmialem Vakif University School of Medicine, İstanbul, Turkey

2Department of General Surgery, Memorial Şişli Hospital, İstanbul, Turkey

This study was presented at the $12^{\text {th }}$ Annual National Endoscopic Laparoscopic Surgery Congress, 22-26 April 2015, Antalya, Turkey.

Address for Correspondence Fatma Ümit Malya e-mail:fumitm@gmail.com

Received: 29.07.2016 Accepted: 03.03.2017

\section{OCopyright 2017} by Turkish Surgical Association
Objective: Laparoscopic distal pancreatectomy is increasingly being used in the surgical treatment of corpus and distal pancreatic tumors. In this study, patients who underwent laparoscopic or open distal pancreatectomy for benign or malignant causes were evaluated in terms of tumor characteristics and perioperative outcomes.

Material and Methods: We retrospectively reviewed data from a total of 27 distal pancreatectomy cases performed for benign or malignant causes in the General Surgery Department between January 2013 and December 2015. Groups were compared according to the demographic characteristics of patients, operation type (laparoscopic or open, with splenectomy or spleen preservation), operation time, surgical site infection (superficial, deep wound infection, or intra-abdominal abscess), pancreatic fistula development, and histopathological examination results.

Results: Both groups were similar in terms of age, sex, and body mass index $(p=0.42)$. Tumor diameter was similar $(p=0.18)$. The total number of resected lymph nodes was similar in both groups $(p=0.6)$. Pancreatic fistula developed in one patient in each group. Mean hospital stay duration and the amount of intraoperative bleeding were similar in both groups. The laparoscopy group had a markedly lower overall morbidity rate $(p=0.08)$. There was no mortality observed in the study subjects.

Conclusion: Laparoscopic distal pancreatectomy can be safely performed as a minimally invasive procedure in experienced centers and in selected cases without increasing perioperative complication rates, particularly in benign cases. Although oncological outcomes are acceptable for malignant cases, future prospective controlled studies are necessary for more reliable evaluation.

Keywords: Laparoscopy, pancreas, oncology

\section{INTRODUCTION}

Today, minimally invasive surgery is being performed safely and effectively to treat a range of conditions. Advantages of minimally invasive techniques include short hospital stays, early return to work, and reduced scar formation $(1,2)$. In comparison to other fields of surgery, minimally invasive surgical interventions are lacking in the field of pancreatic surgery. This lack of innovation may be due to the anatomical location of pancreas, difficulties in surgical technique, and concerns about poor oncological outcomes.

The first laparoscopic distal pancreatic surgery was performed by Gagner and Pomp (3) in 1996. Since that time, additional laparoscopic approaches for pancreatic pathologies have emerged. Several studies have emphasized the advantages of laparoscopic approaches over open surgery, particularly with regard to short-term outcomes $(4,5)$. Laparoscopic distal pancreatectomy is increasingly used in the surgical treatment of corpus and distal pancreatic tumors. Due to concerns of worsening oncological outcomes, laparoscopic pancreatectomy is generally performed in benign disease (6). Nonetheless, this procedure is performed in select malignant cases in conjunction with splenectomy $(7,8)$.

In this study, patients who underwent laparoscopic or open distal pancreatectomy for benign or malignant causes were evaluated in terms of tumor characteristics and perioperative outcomes.

\section{MATERIAL AND METHODS}

In this study, we retrospectively reviewed data from a total of 27 distal pancreatectomy cases performed for benign or malignant causes in the General Surgery Department between January 2013 and December 2015 by scanning the archived data forms. Patients were divided into two groups based on whether the operation technique was laparoscopic or open surgery (Group 1: open surgery and Group 2: laparoscopic surgery). Cases where the operation was initiated as laparoscopic surgery but required conver- 
sion to open surgery were evaluated separately. Groups were compared according to the demographic characteristics of patients, operation type (laparoscopic or open, with splenectomy or spleen preservation), operation time, surgical site infection (superficial, deep wound infection, or intra-abdominal abscess), pancreatic fistula development, and histopathological examination results. The rate of conversion to open surgery was determined. Pancreatic fistulae were evaluated according to the International Study Group of Pancreatic Fistula classification established by Bassi et al (9). This study was conducted in accordance with the ethical standards set out in the Helsinki Declaration. Informed consent was taken from all patients.

\section{Statistical Analysis}

Data were analyzed in collaboration with a biostatistician, using a Student's t-test for parametric data, Mann-Whitney $U$ test for non-parametric data, and the Fischer's exact chi-square test for cross tables. $p<0.05$ and a $95 \%$ confidence interval was considered statistically significant.

\section{RESULTS}

Table 1 summarizes the demographic features, perioperative findings, and histopathological results of the patients who underwent open or laparoscopic surgery. Open surgery was performed in 14 patients, whereas laparoscopic distal pancreatectomy was performed on 10 patients. Both groups were similar in terms of age, sex, and body mass index (BMI) $(p=0.42)$. Tumor diameter was similar $(\mathrm{p}=0.18)$ in both groups; mean tumor diameter was $5.6 \mathrm{~cm}$ in the open surgery group and 3.9 $\mathrm{cm}$ in the laparoscopy group. The total number of resected lymph nodes was similar in both groups $(p=0.6)$. The average number of resected lymph nodes was 12.46 in the open surgery group and 10.38 in the laparoscopy group. Proximal and surrounding surgical border positivity occurred at similar rates in both groups. Spleen-preserving pancreatectomy was performed in two patients in the open surgery group and three patients in the laparoscopy group; there was no significant difference between the groups with regard to the rate of spleen preservation. Two patients in the open surgery group developed surgical site infection, while no patient in the laparoscopy group experienced surgical site infection. Two patients developed intra-abdominal abscess in the open surgery group, while no patient in the laparoscopy group developed abscess. Pancreatic fistula developed in one patient in each group. The fistula observed in the open surgery group was classified as Grade B, while the fistula observed in the laparoscopy group was classified as Grade A. Mean hospital stay duration and the amount of intra-operative bleeding were similar in both groups. The laparoscopy group had a markedly lower overall morbidity rate $(p=0.08)$. There was no mortality observed in the study subjects.

In three patients, the operation was initiated as a laparoscopic surgery but later converted to open surgery. Table 2 shows the demographic features, perioperative findings, and histopathological properties of these cases. Causes of conversion to open surgery were as follows: dissection was difficult due to a previous pancreatitis episode in one patient; one patient had adhesions and splenic vessel invasion related to malignancy; and another patient had a tumor localized to the body of pancreas, which was in close proximity to the portal confluence and therefore presented difficulty in dissection of the area.
Table 1. Demographic features, perioperative findings, and histopathological results in patients operated with open or laparoscopic surgical approach

\begin{tabular}{lccc} 
& $\begin{array}{c}\text { Group 1 } \\
\text { (open) }\end{array}$ & $\begin{array}{c}\text { Group 2 } \\
\text { (laparoscopic) }\end{array}$ & $\mathbf{p}$ \\
\hline $\mathrm{n}$ (=number of patients) & 14 & 10 & \\
Age & $57.7(17-74)$ & $50.7(19-86)$ & 0.32 \\
Sex & 13 & 7 & 0.27 \\
$\quad$-female & 1 & 3 & \\
-male & 26.2 & 27 & 0.61 \\
BMI (kg/m ${ }^{2}$ ) & & & \\
\hline Tumor location & 7 & 3 & 0.42 \\
-body & 7 & 7 & \\
-tail & & & \\
\hline
\end{tabular}

Histopathology

$\begin{array}{lccc}\text {-benign } & 8 & 8 & 0.39 \\ \text {-malignant } & 6 & 2 & \\ \text { Tumor diameter }(\mathrm{cm}) & 5.6 & 3.9 & 0.18 \\ \text { Total lymph nodes } & 12.46(2-33) & 10.38(4-23) & 0.6\end{array}$

$\begin{array}{llll}\text { Surgical border positivity } & & & \\ \text {-proximal } & 0 & 1 & 0.41 \\ \text {-surrounding } & 2 & 0 & 0.49\end{array}$

Splenectomy

$\begin{array}{lccc}\text {-present } & 12 & 7 & 0.62 \\ \text {-absent } & 2 & 3 & \end{array}$

$\begin{array}{lccc}\text { Surgical site infection } & & & \\ \text {-present } & 2 & 0 & 0.49 \\ \text {-absent } & 12 & 10 & \end{array}$

Intra-abdominal abscess

$\begin{array}{cccc}\text {-present } & 2 & 0 & 0.49 \\ \text {-absent } & 12 & 10 & \end{array}$

\begin{tabular}{|lccc|}
\hline $\begin{array}{l}\text { Pancreatic fistula } \\
\text {-present }\end{array}$ & 1 & 1 & 1 \\
\hline -absent & 13 & 9 & \\
\hline Operation time (minute) & 227.5 & 221.5 & 0.83 \\
\hline Intraoperative bleeding $(\mathrm{mL})$ & 125 & 128 & 0.95 \\
\hline Morbidity (patient) & $7(50 \%)$ & $1(10 \%)$ & 0.08 \\
\hline Hospital stay length (days) & 7.1 & 5.6 & 0.11 \\
\hline BMl: body mass index & & & \\
\hline
\end{tabular}

\section{DISCUSSION}

Minimally invasive surgery is preferred in many circumstances due to reduced hospitalization time, accelerated functional recovery, reduced scar formation, and rates of perioperative complication comparable to or better than standard surgical procedures $(1,2)$. In the field of pancreatic surgery, minimally invasive surgery was first performed by Gagner and Pomp (3) in 1996. For all the popularity of 
Table 2. Demographic features, perioperative findings, and histopathological findings in patients who required conversion to open surgery from laparoscopic surgery

Patients who required conversion to open surgery

\begin{tabular}{lc}
$\mathrm{n}$ (=number of patients) & 3 \\
\hline Sex & \\
$\quad$ female & 2 \\
-male & 1 \\
BMI $\left(\mathrm{kg} / \mathrm{m}^{2}\right)$ & $26.1(20-29.3)$
\end{tabular}

Tumor location

$\begin{array}{ll}\text {-body } & 2 \\ \text {-tail } & 1\end{array}$

\begin{tabular}{lc} 
Histopathology & \\
-benign & 1 \\
-malignant & 2 \\
\hline Tumor diameter $(\mathrm{cm})$ & $4.3(1.5-6)$ \\
\hline Total number of lymph nodes & $10(4-16)$ \\
\hline
\end{tabular}

Surgical border positivity

-proximal 0

-surrounding

0

$\begin{array}{ll}\text { Splenectomy } & \\ \text {-present } & 2 \\ \text {-absent } & 1\end{array}$

Wound site infection

-present 0

-absent

3

$\begin{array}{ll}\text { Intra-abdominal abscess } & \\ \text {-present } & 0 \\ \text {-absent } & 3\end{array}$

Pancreatic fistula

-present 1

-absent

2

\begin{tabular}{|lc|}
\hline Operation time (minute) & $230(210-240)$ \\
\hline Intraoperative bleeding $(\mathrm{mL})$ & $266.6(100-500)$ \\
\hline Morbidity (patient) & $1(33 \%)$ \\
\hline Hospital stay length (days) & $6.3(4-8)$ \\
\hline BMI: body mass index & \\
\hline
\end{tabular}

laparoscopic techniques in other fields of surgery, there has been less progress in laparoscopic pancreatic surgery. The reasons for this include the challenging anatomical structure of the pancreas and ethical concerns specific to surgical oncology (2).

Laparoscopic distal pancreatectomy has gained popularity within the recent years as a minimally invasive procedure. It is performed for tumors of the body and tail of the pancreas, and is generally preferred for benign cases (7). Nevertheless, it can also be performed in select malignant cases in conjunction with splenectomy (10).

Study results supporting the use of laparoscopic pancreatic surgery are often based on retrospective data, and it is difficult to conduct comparative prospective studies on this subject. Nevertheless, Riccive et al. (5) compared 41 cases of laparoscopic distal pancreatectomy conducted to treat benign diseases with 40 cases treated by open surgery and evaluated both quality of life outcomes and cost efficacy. They reported no difference between these two groups with regard to postoperative complication rates, pancreatic fistula development, or bleeding. Length of hospital stay was significantly shorter in non-complicated cases. One of the primary advantages of laparoscopic surgery is shorter hospital stay; however, the study conducted by Ricci et al. (5) did not observe a reduction in the length of hospitalization among patients who underwent laparoscopic procedures, possibly because of the high rate of morbidity associated with all types of pancreatic surgeries. Another advantage of laparoscopic surgery is earlier initiation of oral intake, and Riccive et al. (5) observed that patients who underwent laparoscopic procedures were able to tolerate oral intake at earlier time points. Quality of life metrics were also notably improved among the patients who underwent laparoscopic procedures relative to those who underwent open surgery. Laparoscopic surgery was also found to be more cost effective. In the present study, we found that the length of hospitalization remarkably was shorter in the laparoscopic surgery group, although this difference did not meet the criteria for statistical significance $(p=0.11)$. This is consistent with previous studies. In a review conducted by Postlewait et al. (11), evaluating distal pancreatectomy operations performed on malignant cases, laparoscopic distal pancreatectomy was associated with oncologic results comparable to open surgery. Shakyan et al. (12) evaluated outcomes in 196 patients in their cohort study and Adam et al. (4) evaluated short-term outcomes in 1733 cases of distal pancreatectomy. Both studies concluded that laparoscopic distal pancreatectomy can be safely performed with regard to oncological principles. According to these two studies, although bleeding and wound site complications are less common with laparoscopic surgery, there was no significant difference in the overall rate of complications between the two types of surgeries. Nevertheless, long-term prospective studies on this topic are lacking. In the present study, none of the malignant cases exhibited surgical border positivity in pathological results, and the number of resected lymph nodes was similar between the two study groups. As a result, we conclude that laparoscopic distal pancreatectomy may be expected to produce oncological results comparable to open pancreatic surgery. Nonetheless, evaluation of oncological outcomes from a larger number of cases would provide additional evidence for these conclusions. The major advantages of laparoscopy include reduced hospital stay, lower rates of surgical site infection, reduced scar formation, and adaptability to a wide variety of conditions $(13,14)$.

Consistent with reports in the literature, our data demonstrates that perioperative findings and complications are comparable between laparoscopic procedures and open surgery ( $p>0.05)$. 
Postoperative fistula development is the most significant complication of pancreatic surgery. In one multi-center cohort study published in 2015, Sahakyan et al. (12) retrospectively evaluated data from 196 cases and reported postoperative morbidity rates of $32 \%-40 \%$ and postoperative pancreatic fistula rates of $11 \%-27.9 \%$. Majority of these cases were benign; among malignant cases, the rates of morbidity and postoperative fistula development were substantially greater $(31.9 \%$ and $25.1 \%$, respectively). In the present study, pancreatic fistula occurred in $7.1 \%$ of patients in the open surgery group and $8.3 \%$ of patients in laparoscopic surgery group; there was no significant difference between the groups $(p=1.00)$. The laparoscopy group contained fewer malignant cases, which may have contributed to the lower rate of pancreatic fistula development among those patients. Taken together, our results are consistent with the literature in supporting the conclusion that the laparoscopic techniques do not increase the risk of pancreatic fistula development.

In a study evaluating 1733 patients, Adam et al. (4) reported a rate of conversion from laparoscopy to open surgery of $23 \%$. Various studies report this rate at $8 \%-28 \%$ (15). Majority of these cases are malignant disease or other conditions in which dissection is particularly challenging. In our study, three patients (23\%) required conversion to open surgery. The causes for conversion to open surgery in our patients were as follows: difficult dissection due to previous pancreatitis episode; adhesions and splenic vessel invasion related to malignancy; and tumor localization to the body of the pancreas, which was in close proximity to portal confluence.

The primary limitations of our study are the retrospective approach, the relatively low number of patients, and the absence of qualitative measurements of quality of life. Large-scale prospective studies are required to evaluate the potential for laparoscopic surgery approaches in malignant cases. An important aim for these studies should be to determine oncological outcomes in malignant cases with long-term follow-up and to demonstrate that laparoscopic surgery is not associated with additional risk for cases of malignancy.

\section{CONCLUSION}

Laparoscopic distal pancreatectomy can be safely performed as a minimally invasive procedure at experienced centers and in selected cases without increasing perioperative complication rates, particularly in benign cases. Although oncological outcomes are acceptable for malignant cases, future prospective controlled studies are necessary for more reliable evaluation.

Ethics Committee Approval: Authors declared that the research was conducted according to the principles of the World Medical Association Declaration of Helsinki "Ethical Principles for Medical Research Involving Human Subjects" (amended in October 2013).

Informed Consent: Written informed consent was obtained from patients who participated in this study.

Peer-review: Externally peer-reviewed.
Author Contributions: Concept - F.Ü.M., H.K.B., M.H.; Design - F.Ü.M., H.K.B., M.H.; Supervision - F.Ü.M., K.D., M.H.; Resource - F.Ü.M., K.D., O.K.; Materials - F.Ü.M., Y.T., E.K.; Data Collection and/or Processing - F.Ü.M., H.K.B., Y.T.; Analysis and/or Interpretation - F.Ü.M., K.D., O.K.; Literature Search - F.Ü.M., H.K.B., M.H.; Writing Manuscript - F.Ü.M., H.K.B., M.H.; Critical Reviews - F.Ü.M., O.K., K.D.;

Conflict of Interest: No conflict of interest was declared by the authors.

Financial Disclosure: The authors declared that this study has received no financial support.

\section{REFERENCES}

1. Mandrioli M, Inaba K, Piccinini A, Biscardi A, Sartelli M, Agresta F, et al. Advances in laparoscopy for acute care surgery and trauma. World J Gastroenterol 2016; 22: 668-680. [CrossRef]

2. Damoli I, Butturini G, Ramera M, Paiella S, Marchegiani G, Bassi C. Minimally invasive pancreatic surgery -a review. Wideochir InnenTechn Maloinwazyjne 2015; 10: 141-149. [CrossRef]

3. Gagner M, Pomp A. Laparoscopic pylorus-preserving pancreatoduodenectomy. Surg Endosc 1994; 8: 408-410. [CrossRef]

4. Adam MA, Choudhury K, Goffredo P, Reed SD, Blazer D 3rd, Roman SA, et al. Minimally Invasive Distal Pancreatectomy for Cancer: Short-Term Oncologic Outcomes in 1,733 Patients. World J Surg 2015; 39: 2564-2572. [CrossRef]

5. Ricci C, Casadei R, Taffurelli G, Bogoni S, D'Ambra M, Ingaldi C, et al. Laparoscopic Distal Pancreatectomy in Benign or Premalignant Pancreatic Lesions: Is It Really More Cost-Effective than Open Approach? J Gastrointest Surg 2015; 19: 1415-1424. [CrossRef]

6. Matsumoto T, Shibata K, Ohta M, Iwaki K, Uchida H, Yada K, et al. Laparoscopic distal pancreatectomy and open distal pancreatectomy: a non randomized comparative study. Surg Laparosc Endosc Percutan Tech 2008; 18: 340-343. [CrossRef]

7. lacobone M, Citton M, Nitti D. Laparoscopic distal pancreatectomy: up-to-date and literature review.World J Gastroenterol 2012; 18: 5329-5337. [CrossRef]

8. Kang CM, Lee SH, Lee WJ. Minimally invasive radical pancreatectomy for left-sided pancreatic cancer: current statusand future perspectives. World J Gastroenterol 2014; 20: 2343-2451 [CrossRef]

9. Bassi C, Dervenis C, Butturini G, Fingerhut A, Yeo C, Izbicki J, Neoptolemos J, Sarr M, Traverso W, Buchler M. Postoperative pancreatic fistula: an international study group (ISGPF) definition. Surgery 2005; 138: 8-13 [PMID: 16003309 DOI: 10.1016/j. surg.2005.05.00

10. DiNorcia J, Schrope BA, Lee MK, Reavey PL, Rosen SJ, Lee JA, et al. Laparoscopic distal pancreatectomy offers shorter hospital stays with fewer complications .J Gastrointest Surg 2010; 14: 1804-1812. [CrossRef]

11. Postlewait LM, Kooby DA. Laparoscopic distal pancreatectomy for adenocarcinoma: safe and reasonable? J Gastrointest Oncol 2015; 6: 406-417.

12. Sahakyan MA, Kazaryan AM, Rawashdeh M, Fuks D, Shmavonyan M, Haugvik SP, et al. Laparoscopic distal pancreatectomy for pancreatic ductal adenocarcinoma: results of a multicenter cohort study on 196 patients. Surg Endosc 2015; 30: 3409-3418. [CrossRef]

13. Sui CJ, Li B, Yang JM, Wang SJ, Zhou YM. Laparoscopic versus open distal pancreatectomy: a meta-analysis.Asian J Surg 2012; 35: 1-8. [CrossRef]

14. Jusoh AC, Ammori BJ. Laparoscopic versus open distal pancreatectomy: a systematic review of comparative studies. Surg Endosc 2012; 26: 904-913. [CrossRef]

15. Topgul K, S. Yuruker S, Koca B, Kesicioğlu T. Spleen-preserving laparoscopic distal pancreatectomy: Two cases and review of the technique. Turk J Surg 2013; 29: 139-143. [CrossRef] 